\title{
Etiology of exudative pleural effusions in adults in North Lebanon
}

\author{
Wassim Khalil Kalaajieh MD PhD \\ Public Health Faculty - Lebanese University, Tripoli, Lebanon
}

\section{WK Kalaajieh. Etiology of exudative pleural effusions in adults in North Lebanon. Can Respir J 2001;8(2):93-97.}

OBJECTIVE: To establish the clinical pattern and etiology of exudative pleural effusions in adults in North Lebanon.

MATERIALS AND METHODS: All patients aged 21 years and older who were admitted with exudative pleural effusions to the Husseini Hospital, Tripoli, North Lebanon, between 1997 and 1999 were studied prospectively.

RESULTS: Of 165 patients with exudative pleural effusions, $114(69.1 \%)$ were men and $51(30.9 \%)$ were women. The most frequent cause of exudative pleural effusions was tuberculosis (43.7\%), followed by malignancy (32.1\%). The majority (88.7\%) of malignant pleural effusions were due to lung cancer. Tuberculous effusions were more frequent in the first five decades of life $(66.7 \%)$ and were the most common type of pleural effusion, accounting for $68.6 \%$ of patients younger than 50 years of age. Malignant effusions were more frequent among the older age groups, with $73.6 \%$ of patients with malignant effusions being older than 50 years of age. Most types of exudative pleural effusions showed a preference for the right side of the thorax. Of the diagnostic procedures used in the present study, the most useful were histological examination and culture of pleural biopsies.

CONCLUSIONS: In North Lebanon, the clinical pattern and etiology of exudative pleural effusions are similar to those in the developing countries; the most frequent cause of pleural exudates is tuberculosis, followed by malignancy, particularly malignancy due to lung cancer.

Key Words: Lebanon; Malignancy; Pleural effusions; Tuberculosis

\section{Étiologie des épanchements pleuraux exsuda- tifs chez les adultes au Nord du Liban}

OBJECTIF : Établir l'étiologie et le tableau clinique des épanchements pleuraux exsudatifs chez les adultes au Nord du Liban.

PATIENTS ET MÉTHODE : Étude rétrospective de tous les patients âgés de 21 ans et plus, admis à l'hôpital Husseini, à Tripoli, au Nord du Liban, entre 1997 et 1999, pour un épanchement pleural exsudatif.

RÉSULTATS : Des 165 patients admis, 114 (69,1\%) étaient des hommes et $51(30,9 \%)$, des femmes. La cause la plus fréquente d'épanchement pleural exsudatif était la tuberculose $(43,7 \%)$, suivie des tumeurs malignes $(32,1 \%)$. La plupart $(88,7 \%)$ des épanchements pleuraux malins étaient dus à un cancer du poumon. La tuberculose constituait la principale cause d'épanchement pleural au cours des cinq premières décennies de vie $(66,7 \%)$, touchant $68,6 \%$ des patients de moins de 50 ans, tandis que le cancer se rencontrait surtout chez les patients de plus de 50 ans, touchant 73,6\% d'entre eux. Les épanchements pleuraux exsudatifs se situaient de préférence du côté droit du thorax. L'examen histologique et la culture des prélèvements pleuraux par biopsie se sont avérés les interventions diagnostiques les plus utiles dans le cadre de la présente étude.

CONCLUSION : Les épanchements pleuraux exsudatifs au Nord du Liban ont une étiologie et un tableau clinique semblables à ceux des pays en voie de développement, c'est-à-dire qu'ils ont pour principale cause la tuberculose, suivie des tumeurs malignes, notamment du cancer du poumon.
A great variety of disease processes can give rise to exudative pleural effusions, but the principal ones to be considered in a patient with a pleural exudate are tuberculosis and malignancy $(1,2)$. The frequencies of different causes of exudative pleural effusions that are reported in a particular study depend on the patient population used, whether the pa- 
TABLE 1

Criteria for diagnosis of tuberculous pleural effusions

\begin{tabular}{lc}
\hline Criteria & Number of patients (\%) \\
\hline Presence of epithelioid cell granulomas with or without caseating necrosis, and positive staining for acid-fast & 15 (20.8) \\
bacilli in pleural biopsy specimens & $7(9.7)$ \\
Presence of epithelioid cell granulomas with or without caseating necrosis in pleural biopsy specimens plus: & $30(41.7)$ \\
Positive acid-fast bacilli and/or Mycobacterium tuberculosis isolated from respiratory tract specimens & \\
Clinical and radiological response to antituberculosis chemotherapy & $4(5.6)$ \\
Negative pleural biopsy but tuberculin conversion, lymphocyte predominant exudate, and clinical and & $16(22.2)$ \\
radiological response to antituberculosis chemotherapy with: & $72(100)$ \\
Presence of acid-fast bacilli in respiratory specimens & Absence of acid-fast bacilli in respiratory specimens \\
Total
\end{tabular}

TABLE 2

Etiological diversity of exudative pleural effusions in adults in North Lebanon

\begin{tabular}{lccc}
\hline $\begin{array}{l}\text { Cause of } \\
\text { pleural effusion }\end{array}$ & $\begin{array}{c}\text { Number of } \\
\text { patients (\%) }\end{array}$ & $\begin{array}{c}\text { Number of } \\
\text { men/women (ratio) }\end{array}$ & $\begin{array}{c}\text { Mean age } \\
\text { (years) }\end{array}$ \\
\hline Tuberculosis & $72(43.7)$ & $57 / 15(3.8: 1)$ & $36.5 \pm 16.2$ \\
Malignancy & $53(32.1)$ & $33 / 20(1.6: 1)$ & $63.4 \pm 11.9$ \\
Empyema & $22(13.3)$ & $13 / 9(1.4: 1)$ & $52.7 \pm 15.2$ \\
Parapneumonia & $18(10.9)$ & $11 / 7(1.6: 1)$ & $59.4 \pm 16.5$ \\
Total & $165(100)$ & $114 / 51(2.3: 1)$ & $53.6 \pm 16.9$ \\
\hline
\end{tabular}

tients are investigated and treated in a primary care setting or a tertiary referral centre, and the geographical region where the study is conducted $(3,4)$. In Tripoli, North Lebanon, where the incidence of tuberculosis is relatively high (43 per 100,000 population in 1996), the distinction between tuberculous and nontuberculous causes of exudative pleural effusions is an important clinical problem (5). A prospective study was performed to define the causes of exudative pleural effusions treated in a tertiary medical centre situated in an urban area.

\section{MATERIALS AND METHODS}

Data collection: A prospective study was conducted of the medical records and chest radiographs of consecutive cases of exudative pleural effusions referred to the internal medicine service of the Husseini Hospital, Tripoli, Lebanon, during a three-year period from January 1997 to December 1999. All patients aged 21 years and older who presented with pleural effusions routinely underwent tuberculin skin testing, abdominal ultrasound and diagnostic thoracentesis to obtain pleural fluid specimens for cell count, cytology, Gram and Ziehl-Neelsen stain, and bacterial and tuberculosis culture. Total protein and lactate dehydrogenase levels were obtained for both serum and pleural fluid specimens to distinguish exudates from transudates according to Light's criteria (6). Closed percutaneous pleural biopsy was routinely performed with the Abrams needle (7) or Tru-cut needle (8). As a routine, pleural biopsy was performed using the Abrams needle; the Tru-cut needle was used for pleural biopsy only in situations where the Abrams needle biopsy was negative and where computed tomography (CT) of the thorax showed marked pleural thickening in addition to the pleural effusion. None of the patients underwent more invasive procedures, such as open or thoracoscopic pleural biopsy.

Clinical definitions: Table 1 shows the diagnostic criteria for tuberculous pleural effusions. Malignant or neoplastic pleural effusions were confirmed by positive pleural biopsy and/or positive pleural fluid cytology. Parapneumonic effusions were those that occurred in association with bacterial pneumonia, and empyema was diagnosed when the effusion fluid was purulent or grew a pathogenic organism on culture, or if it was culture-negative on Gram stain (ie, a positive Gram stain) $(9,10)$.

Pleural effusion size: The size of the pleural effusion seen on chest radiograph at presentation was graded as 'small' when the costophrenic angle was obliterated but the hemidiaphragm was not covered, 'medium' when it filled up to half of the hemithorax or 'large' when it filled up more than half of the hemithorax. For patients with bilateral effusions, the size of the larger effusion was recorded.

Statistical analysis: Results are expressed as the mean \pm SD. Differences between groups were compared using the twotailed, unpaired Student's $t$ test or one-way ANOVA, with Newman-Keuls' multiple comparisons post hoc test, when appropriate, for continuous variables. The $\chi^{2}$ test (Yates' corrected, when applicable) was used to analyze categorical data. $\mathrm{P}<0.05$ for a two-tailed test was considered statistically significant.

\section{RESULTS}

Of the 165 patients between 21 and 80 years of age (54 \pm 16.9 years) with exudative pleural effusions during the study period, $114(69.1 \%)$ were men aged $46 \pm 15.9$ years and $51(30.9 \%)$ were women aged $52 \pm 16.4$ years. Female patients were significantly older $(\mathrm{P}=0.05)$, and the male to female ratio was 2.3:1. The etiological distribution of pleural effusions, with the number of patients in each etiological group and the mean age of the group, are shown in Table 2. The two most common causes of exudative pleural effusions were tuberculosis (43.7\%) and malignancy (32.1\%). Patients with tuberculous pleural effusions were significantly younger than the rest $(\mathrm{P}<0.05)$.

The age distributions of patients with tuberculous and ma- 


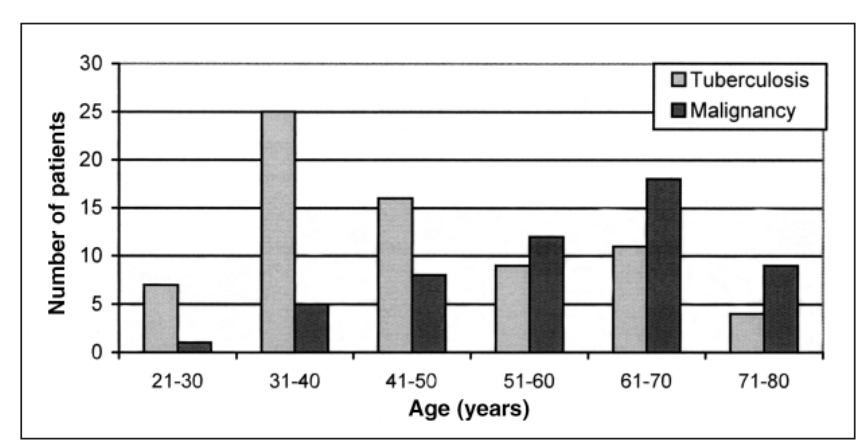

Figure 1) Age distribution of patients with tuberculous and malignant pleural effusions

lignant pleural effusions are shown in Figure 1. Tuberculous effusions were more frequent in the first five decades of life (48 of 72 [66.7\%] cases) and were the most common type of pleural effusion, accounting for 48 of 70 (68.6\%) patients younger than 50 years of age. Malignant effusions were more frequent among the older age groups - 39 of $53(73.6 \%)$ patients with malignant effusions were older than 50 years of age - and accounted for $41.1 \%$ of the 95 cases in this age range. The majority of patients with empyema (18 of 22 [81.8\%]) and parapneumonic effusion (14 of 18 [77.8\%]) were older than 50 years of age.

In patients with tuberculous pleural effusions, the diagnostic yield of Abrams needle biopsy for the presence of caseous granulomas in pleural biopsy tissue samples was 52 of $72(72.2 \%)$ patients, while that for Tru-cut needle biopsy of seven patients was $100 \%$. In patients with malignant pleural effusions, the diagnostic yield of Abrams needle biopsy was 24 of 53 (45.3\%) patients, while that for Tru-cut needle biopsy of two patients was $100 \%$.

Malignant pleural effusions were confirmed by positive pleural biopsy in 16 patients, positive pleural fluid cytology in 27 , and positive pleural biopsy and positive pleural fluid cytology in 10 . Thus, of 53 patients with malignant effusions, pleural fluid cytology was positive in 37 (69.8\%), while pleural biopsy was positive in $26(49.1 \%)$. Table 3 lists the primary neoplasms responsible for malignant effusions. The majority (88.7\%) of malignant pleural effusions were due to lung cancer.

Culture of empyema fluid grew Klesbsiella pneumoniae in eight patients, Streptococcus pneumoniae in four, Staphylococcus aureus in two and Streptococcus species in two. No bacterial organism was isolated from the empyema fluid of six patients. Of the patients with parapneumonic effusion, $K$ pneumoniae was isolated in the sputum of four patients and Haemophilus influenzae was isolated in two. The rest of the patients did not have a pathogen isolated. Blood cultures were negative in all patients with parapneumonic effusion. Serological tests for Mycoplasma, Chlamydia and Legionella species were negative in all patients with parapneumonic effusions.

In 106 patients (64.2\%), pleural effusions occurred only on the right side of the thorax; in 52 (31.5\%), only on the left; and in seven (4.3\%), both sides were involved. Most types of

\section{TABLE 3}

\section{Neoplasms causing malignant pleural effusions}

\section{Type of primary neoplasm}

Adenocarcinoma of the lung Number of patients (\%)

Squamous cell carcinomas of the lung

$31(58.5)$

Small cell lung cancer

$8(15.1)$

Mesothelioma

$5(9.4)$

Large cell carcinoma of the lung

$5(9.4)$

Adenocarcinoma of unknown primary

malignancy

Total

$3(5.7)$

$1(1.9)$

$53(100)$

\section{TABLE 4}

Size of pleural effusion according to etiology

\begin{tabular}{lcccc}
\hline & \multicolumn{4}{c}{ Pleural effusion size } \\
Etiology & $\begin{array}{c}\text { Large } \\
\mathbf{( n [ \% ] )}\end{array}$ & $\begin{array}{c}\text { Medium } \\
\mathbf{( n [ \% ] )}\end{array}$ & $\begin{array}{c}\text { Small } \\
\mathbf{( n [ \% ] )}\end{array}$ & Total \\
\hline Tuberculosis & $9(12.5)$ & $42(58.3)$ & $21(29.2)$ & 72 \\
Malignancy & $28(52.8)$ & $17(32.1)$ & $8(15.1)$ & 53 \\
Empyema & - & $16(72.8)$ & $6(27.2)$ & 22 \\
Parapneumonia & - & $9(50)$ & $9(50)$ & 18 \\
Total & $37(22.4)$ & $84(50.9)$ & $44(26.7)$ & 165 \\
\hline
\end{tabular}

pleural effusions showed a preference for the right side. Tuberculous pleural effusions were right sided in $62.2 \%$ of patients, while malignant effusions were right sided in $65.5 \%$ of patients. Table 4 shows the distribution of size of the pleural effusions according to etiology. Of the 37 large effusions, $28(75.7 \%)$ were caused by malignancy. While 28 of 53 $(52.8 \%)$ malignant effusions were large in size at the time of presentation, effusions of similar size were only seen in nine of $72(12.5 \%)$ effusions that were tuberculous in etiology $\left(\chi^{2}=24.643, \mathrm{P}<0.001\right)$.

\section{DISCUSSION}

In the present study, the most common etiology of exudative pleural effusions was tuberculosis, which accounted for $44 \%$ of all cases. In general, the proportion of pleural effusions due to tuberculosis varies and is likely to reflect the local incidence of the disease, which is high in North Lebanon at 43 cases per 100,000 population. Other authors have reported tuberculosis as the most frequent cause of pleural effusions in areas where the incidence of tuberculosis is high $(4,11)$. Because the incidence of active tuberculous infection in the Eastern Mediterranean region in 1996 was 129 cases per 100,000 persons compared, for example, with 10 cases per 100,000 in the United States and Canada, tuberculosis is likely to be a frequent if not the leading cause of exudative pleural effusions in this part of the world (12).

The greater frequency of tuberculous effusions among our patients was even more pronounced among those aged 50 years or younger, in whom tuberculosis was the cause of about $69 \%$ of cases of pleural effusions. The mean age (36.5 years) of patients with tuberculous pleural effusions was much lower than that of patients with most other types of pleural effusion, 
in agreement with the findings in other developing countries $(13,14)$ and in contrast to the findings in developed countries, where the age has steadily increased (15-18).

Bacteriological confirmation for Mycobacterium tuberculosis in pleural fluid culture is often not obtained because the mycobacterial population in tuberculous pleural effusion is generally small and cultures of pleural fluid specimens are generally positive in only up to about $30 \%$ of cases $(15,19)$. The presence of granulomatous inflammation on histological examination of pleural biopsy specimens is frequently used as a diagnostic criterion for pleural tuberculosis $(20,21)$. Acid-fast bacilli were stained positive in granulomas of pleural biopsy specimens from $20.8 \%$ of our patients with tuberculous effusions. This is comparable with the range of $20 \%$ to $40 \%$ described in the literature $(20,22,23)$.

Malignancy was the second most common cause of exudative pleural effusions in our study and the most frequent cause among patients older than 50 years of age. Others have also made the same observation (4). Malignancy was the cause of effusions in $32 \%$ of our patients, within the range of prevalence ( $15 \%$ to $48 \%$ ) reported in other published series $(4,24,25)$. In keeping with reports in the literature $(4,26)$, carcinoma of the lung was the most common neoplasm to cause malignant pleural effusion in our patients. Compared with pleural fluid cytology, needle pleural biopsy has a lower yield for the diagnosis of malignant pleural effusions (27-29). This is borne out by our results, which showed that $70 \%$ of patients with malignant effusions had positive pleural fluid cytology, while only $49 \%$ had positive pleural biopsy findings. This indicates that cytological evaluation of pleural fluid is more efficacious in the diagnosis of malignant pleural effusion than percutaneous pleural biopsies.

The right-sided dominance of tuberculous pleural effusion in our patients is in agreement with the observations of others $(19,20,30,31)$. The reason for this predilection is not clear. Although other authors have not found a preference of neoplastic effusions for a particular side (4), malignant pleural effusions in our patients occurred much more commonly on the right side than on the left.

The majority of massive pleural effusions are due to malignancy (32). This is also evident from our results, which showed that most of the large pleural effusions were caused by malignancy.

In North Lebanon, the distinction between tuberculous and nontuberculous causes of exudative pleural effusions, especially malignancy, is an important clinical problem. Malignant effusions tended to occur in an older population and were likely to be large at presentation, but the considerable overlap of these characteristics in both types of effusion means that they cannot be used to distinguish one from the other in an individual patient. The diagnosis eventually depends on pleural biopsy findings, pleural fluid cytological and microbiological examinations, and, occasionally, the response to antituberculosis chemotherapy. There is a large literature related to the use of adenosine desaminase level in pleural fluid in diagnosing tuberculous pleural effusions because of its high sensitivity and specificity (33-35).
Effusions with an etiology of parapneumonia or empyema accounted for $24 \%$ of all of our cases. It is estimated that about $40 \%$ of patients with pneumonia develop a concomitant pleural effusion (10), although some studies show the incidence of this complication of pneumonia to be less than $20 \%$ (36). In one series (4), parapneumonic effusion together with empyema accounted for $14 \%$ of all cases of pleural effusions, both transudative and exudative. The percentage of positive pleural fluid cultures in our patients with empyema was surprisingly high despite the liberal prescribing of antibiotics by primary care physicians.

During the study period, only five cases of systemic lupus erythematosus (SLE) were registered in our hospital, and none had pleural effusion. This observation agrees with what has been previously published about the clinical expression of SLE in patients in Lebanon (37) and other Arabic countries (38-41). The presence of differences in the symptomatology of SLE in Arabic patients may be influenced by racial and ethnic differences (eg, histocompatibility leukocyte antigen), and geographical and environmental factors (eg, weather, viruses) (41-45).

The etiologies of pleural effusions observed in this study were similar to those found in other Arabic countries $(46,47)$. However, the comparison with experience in a country such as Canada, with a low prevalence of tuberculosis, shows great differences. Among these differences is the higher exposure to asbestos in Canada, with the main causes of effusions being pleural mesothelioma and lung cancer $(48,49)$. Among workers exposed to asbestos, there are two cases of asbestos-related lung cancer for every case of mesothelioma (50). Thus, it seems likely that the most frequent cause of exudative pleural effusions in Canada is lung cancer, followed by pleural mesothelioma, with tuberculosis being much less frequent.

\section{CONCLUSIONS}

The most frequent cause of exudative pleural effusions seen in the internal medicine service of our hospital is tuberculosis, followed by malignancy, particularly lung cancer. This etiological distribution may be typical of regions that, like North Lebanon, have a high incidence of tuberculosis.

\section{REFERENCES}

1. Light RW. Approach to the patient. In: Light RW, ed. Pleural Diseases. Philadelphia: Lea \& Febiger, 1990:75-84.

2. Health and Public Policy Committee, American College of Physicians. Diagnostic thoracentesis and pleural biopsy in pleural effusions. Ann Intern Med 1985;103:799-802.

3. Marel M, Zrustova M, Stasny B, Light RW. The incidence of pleural effusion in a well-defined region: epidemiologic study in central Bohemia. Chest 1993;104:1486-9.

4. Valdes L, Alvarez D, Valle JM, Pose A, San Jose E. The etiology of pleural effusions in an area with high incidence of tuberculosis. Chest 1996;109:158-62.

5. Kalaajieh WK. Epidemiology of tuberculosis in Lebanon. Int J Tuberc Lung Dis 1999;3:774-7.

6. Light RW. Pleural Diseases, 2nd edn. Philadelphia: Lea \& Febiger, 1992:42.

7. Abrams LD. A pleural punch biopsy. Lancet 1958;i:30-1.

8. McLeod DT, Ternouth I, Nkanza N. Comparison of the Tru-cut biopsy needle with the Abrams punch for pleural biopsy. Thorax 1989;44:794-6. 
9. Light RW. Parapneumonic effusions and infections of the pleural space. In: Light RW, ed. Pleural Diseases, 2nd edn. Philadelphia: Lea \& Febiger, 1990:129-49.

10. Hamm H, Light RW. Parapneumonic effusion and empyema. Eur Respir J 1997;10:1150-6.

11. Fontan Bueso J, Verea Hernando H, Garcia-Buela JP, Dominguez Juncal L, Martin Egana MT, Montero Martinez MC. Diagnostic value of simultaneous determination of pleural adenosine deaminase and pleural lysozyme/serum lysozyme ratio in pleural effusions. Chest 1988;93:303-7.

12. Dye C, Scheele S, Dolin P, Pathania V, Raviglione MC. Consensus statement. Global burden of tuberculosis: Estimated incidence, prevalence and mortality by country. WHO Global Surveillance and Monitoring Project. JAMA 1999;282:677-86

13. Sinha PK, Sinha BB, Sinha AR. Diagnosing tuberculous pleural effusion: comparative sensitivity of mycobacterial culture, histopathology and adenosine deaminase activity. J Assoc Physicians India 1985;33:644-5.

14. Arriero JM, Romero S, Hernandez L, et al. Tuberculous pleurisy with or without radiographic evidence of pulmonary disease. Is there any difference? Int J Tuberc Lung Dis 1998;2:513-7.

15. Moudgil H, Sridhar G, Leitch AG. Reactivation disease: the commonest form of tuberculous pleural effusion in Edinburgh, 1980-1991. Respir Med 1994;88:301-4.

16. Seibert AF, Haynes J Jr, Middleton R, Bass JB Jr. Tuberculous pleural effusion: twenty-year experience. Chest 1991;99:883-6.

17. Epstein DM, Kline LR, Albelda SM, Miller WT. Tuberculous pleural effusions. Chest 1987;91:106-9.

18. Dutt AK, Moers D, Stead WW. Tuberculous pleural effusion: 6-month therapy with isoniazid and rifampin. Am Rev Respir Dis 1992;145:1429-32.

19. Berger HW, Mejia E. Tuberculous pleurisy. Chest 1973;63:88-92.

20. Scharer L, McClement JH. Isolation of tubercle bacilli from needle biopsy specimens of parietal pleura. Am Rev Respir Dis 1968;97:466-8.

21. Levine H, Metzger W, Lacera D, Kay L. Diagnosis of tuberculous pleurisy by culture of pleural biopsy specimen. Arch Intern Med 1970;126:169-71.

22. Kirsch CM, Kroe DM, Jensen WA, Kagawa FT, Wehner JH, Campagna AC. A modified Abrams needle biopsy technique. Chest 1995;108:982-6.

23. Centers for Disease Control. Tuberculosis and human immunodeficiency virus infection: recommendations of the Advisory Committee for the Elimination of Tuberculosis (ACET). MMWR Morb Mortal Wkly Rep 1989;38:236-8,243-50.

24. Thivolet-Bejui F. [Pleural cytopathology: diagnosis of primary and metastatic tumors]. Ann Pathol 1999;19:387-93.

25. Peterman TA, Speicher CE. Evaluating pleural effusions: a two-stage laboratory approach. JAMA 1984;252:1051-3.

26. Rodriguez-Panadero F. Malignant pleural diseases. Monaldi Arch Chest Dis 2000;55:17-9.

27. Kumar ND, Bhatia A, Misra K, Suri JC. Comparison of pleural fluid cytology and pleural biopsy in the evaluation of pleural effusion. J Indian Med Assoc 1995;93:307-9

28. Prakash UBS, Reiman HM. Comparison of needle biopsy with cytologic analysis for the evaluation of pleural effusion: analysis of 414 cases. Mayo Clin Proc 1985;60:158-64.

29. Sahn SA. Malignant pleural effusions. In: Fishman AP, ed. Pulmonary Diseases and Disorders, 2nd edn. New York: McGraw Hill, 1989:2159-70.
30. Sahn SA. Pleural manifestations of pulmonary disease. Hosp Pract (Hosp Ed) 1981;16:73-9,83-5,89.

31. Johnston RF, Green RA. Pleural inflammation and pleural effusion. In: Baum GL, Wolinsky E, eds. Textbook of Pulmonary Diseases, 3rd edn. Boston: Little, Brown and Company, 1983:1299-325.

32. Maher GG, Berger HW. Massive pleural effusion: malignant and nonmalignant causes in 46 patients. Am Rev Respir Dis 1972;105:458-60

33. Banales JL, Pineda PR, Fitzgerald JM, Rubio H, Selman M, Salazar-Lezama M. Adenosine deaminase in the diagnosis of tuberculous pleural effusions. A report of 218 patients and review of the literature. Chest 1991;99:355-7.

34. Salazar-Lezama M, Quiroz-Rosales H, Banales-Mendez JL, et al. Diagnostic methods of primary tuberculous pleural effusion in a region with high prevalence of tuberculosis. A study in Mexican population. Rev Invest Clin 1997;49:453-6.

35. Hamada T, Sanaka M, Hata E, Hasegawa T. [Pleural adenosine deaminase levels in tuberculous pleurisy - its diagnostic performance under the different prevalences in the different age of population]. Jpn J Thorac Cardiovasc Surg 1998;46:51-7.

36. Sow O, Frechet M, Diallo AA, et al. Community acquired pneumonia in adults: a study comparing clinical features and outcome in Africa (Republic of Guinea) and Europe (France). Thorax 1996;51:385-8.

37. Uthman I, Nasr F, Kassak K, Masri AF. Systemic lupus erythematosus in Lebanon. Lupus 1999;8:713-5.

38. Alballa SR. Systemic lupus erythematosus in Saudi patients. Clin Rheumatol 1995;14:342-6.

39. al-Attia HM, George S. Characterization of systemic lupus erythematosus in patients in U.A.E. Clin Rheumatol 1995;14:171-5.

40. al-Attia HM. Clinicolaboratory profile of 33 Arabs with systemic lupus erythematosus. Postgrad Med J 1996;72:677-9.

41. Al-Jarallah K, Al-Awadi A, Siddiqui H, et al. Systemic lupus erythematosus in Kuwait - hospital based study. Lupus 1998;7:434-8.

42. Wysenbeek AJ, Leibovici L, Weinberger A, Guedj D. Expression of systemic lupus erythematosus in various ethnic Jewish Israeli groups. Ann Rheum Dis 1993;52:268-71.

43. Blanco FJ, de la Mata J, Gomez-Reino JJ, et al. [Clinical and serological manifestations of 307 Spanish patients with systemic lupus erythematosus. Comparison with other ethnic groups]. Rev Clin Esp 1995; 195:534-40.

44. Levy Y, George J, Hojnic M, et al. Comparison of clinical and laboratory parameters for systemic lupus erythematosus activity in Israelis versus Europeans. Isr J Med Sci 1996;32:100-4.

45. Molina JF, Molina J, Garcia C, Gharavi AE, Wilson WA, Espinoza LR. Ethnic differences in the clinical expression of systemic lupus erythematosus: a comparative study between African-Americans and Latin Americans. Lupus 1997;6:63-7.

46. Al-Alusi F. Pleural effusion in Iraq: a prospective study of 100 cases. Thorax 1986;41:492-3.

47. al-Qorain A, Larbi EB, al-Muhanna F, Satti MB, Baloush A, Falha K. Pattern of pleural effusion in Eastern Province of Saudi Arabia: a prospective study. East Afr Med J 1994;71:246-9.

48. McDonald JC, Armstrong B, Case B, et al. Mesothelioma and asbestos fiber type. Evidence from lung tissue analyses. Cancer 1989;63:1544-7.

49. Smith AH, Wright CC. Chrysotile asbestos is the main cause of pleural mesothelioma. Am J Ind Med 1996;30:252-66.

50. Gennaro V, Finkelstein MM, Ceppi M, et al. Mesothelioma and lung tumors attributable to asbestos among petroleum workers. Am J Ind Med 2000;37:275-82 


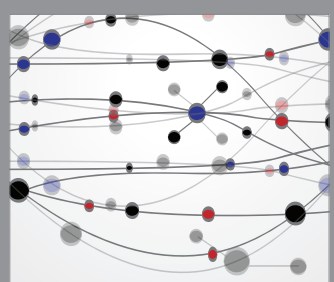

The Scientific World Journal
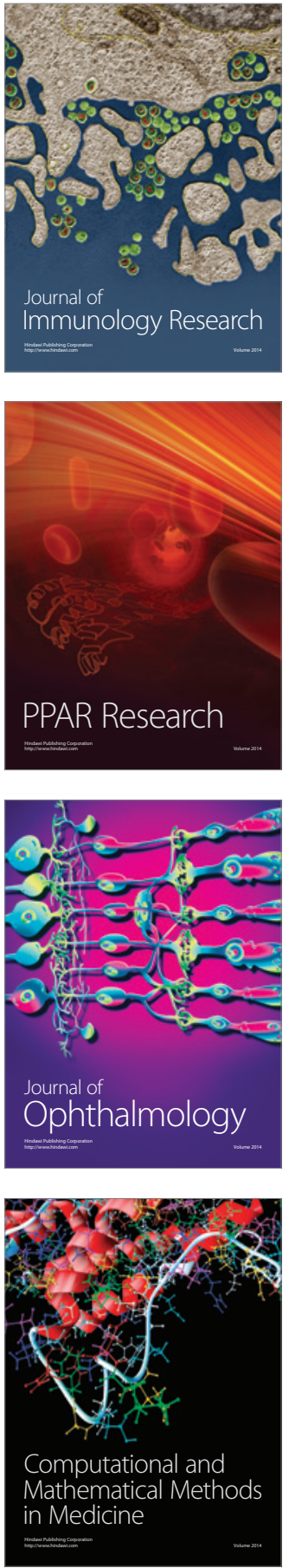

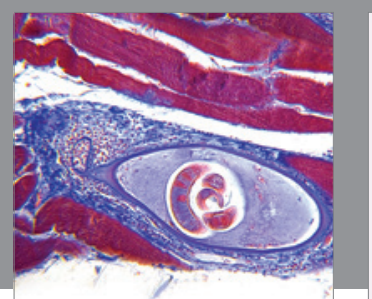

Gastroenterology Research and Practice

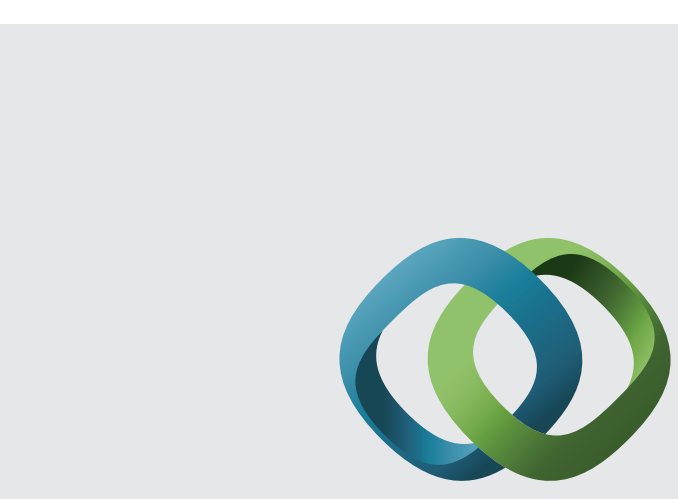

\section{Hindawi}

Submit your manuscripts at

http://www.hindawi.com
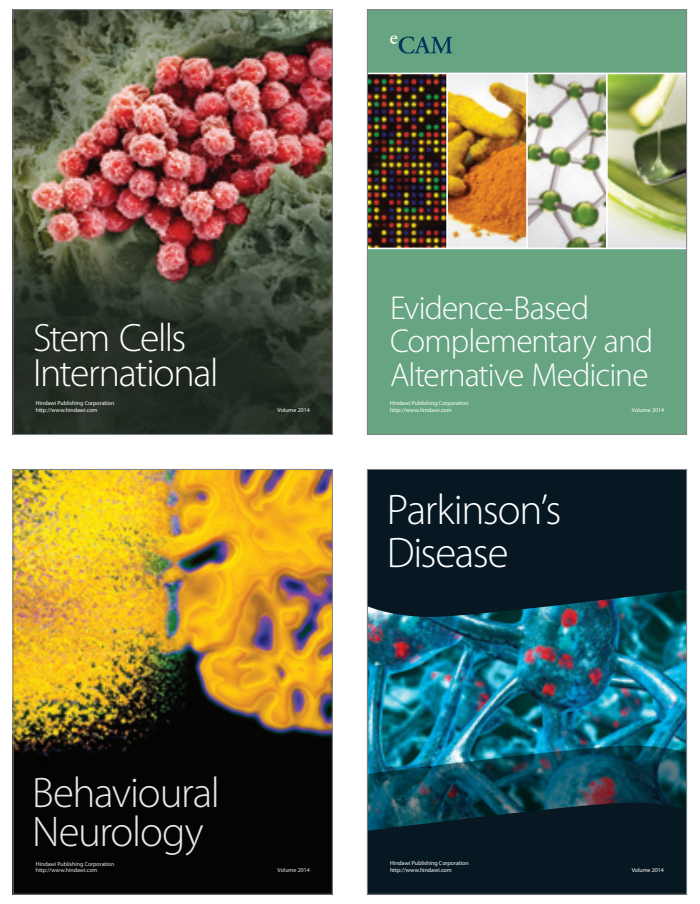
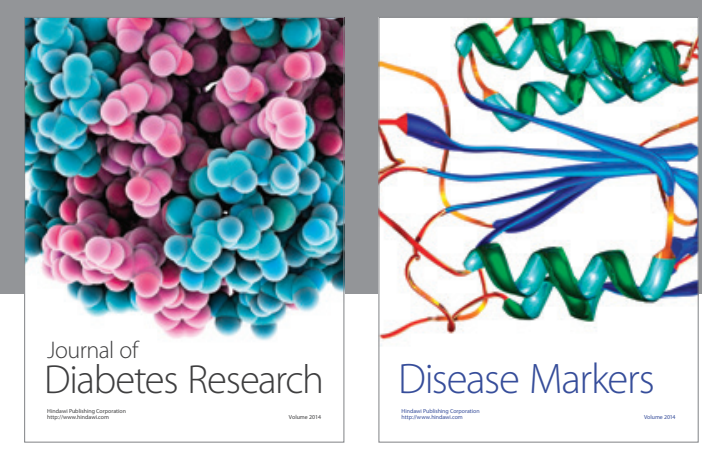

Disease Markers
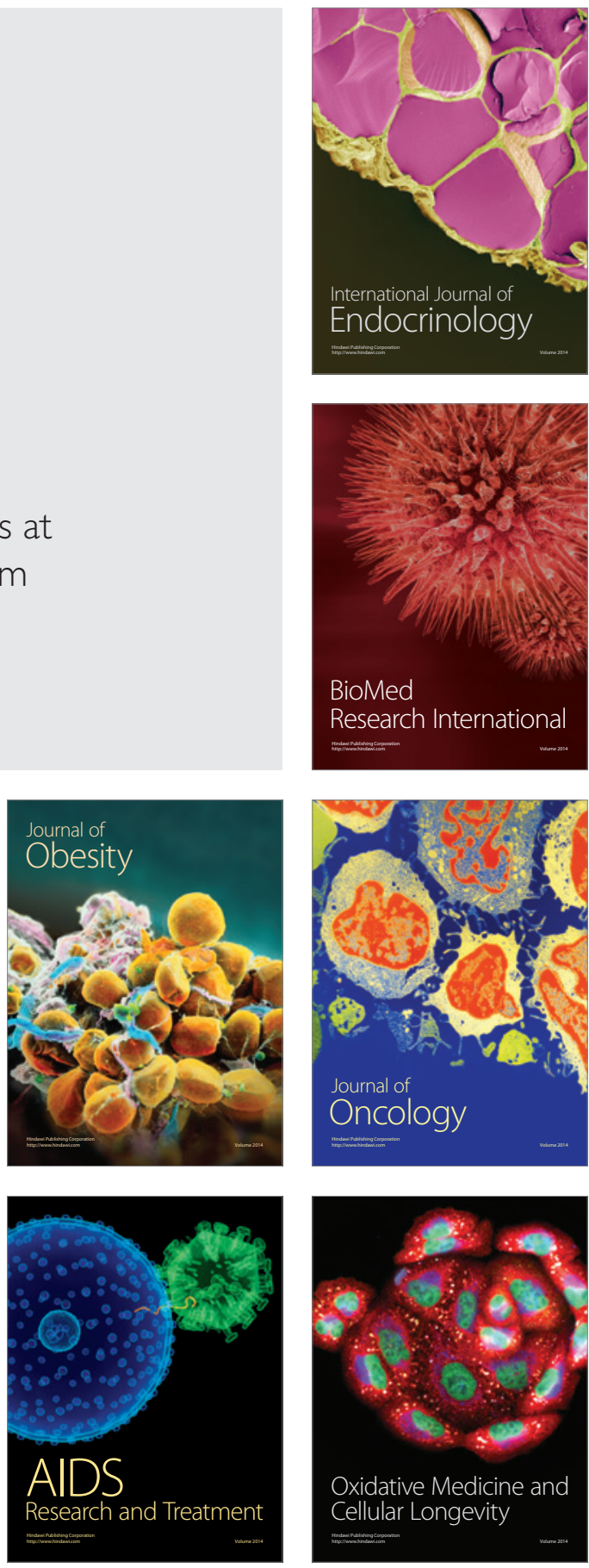